\title{
EREBEA
}

Revista de Humanidades

y Ciencias Sociales

NúM. 7 (2017), pp. 253-274

ISSN: 0214-0691

\section{SAN SEBASTIÁN EN EL NATURALISMO ESCULTÓRICO GRANADINO. ESTÉTICA Y SÍMBOLO DE UNA ICONOGRAFÍA MARTIRIAL}

\author{
José Antonio Peinado Guzmán e Isaac Palomino Ruiz \\ Universidad de Granada
}

RESUMEN

La figura de San Sebastián supone una de las devociones más arraigadas en el mundo cristiano desde la Alta Edad Media. En este sentido, la popularidad que alcanzó este santo, le hizo merecedor de numerosos patronazgos y del afecto del pueblo, por lo que todo ello se manifestó artísticamente en numerosas imágenes. El presente trabajo pretende analizar las diferentes tallas que surgieron en el entorno granadino, desde finales del siglo XVI hasta mediados del XVII, por la mayor calidad plástica de las mismas, además de estar imbuidas por unas connotaciones históricas determinadas, que influyeron en la extensión, por algunas comarcas, de la devoción a San Sebastián.

Palabras Clave

Escultura; Granada; Siglos XVI-XVII; Alonso de Mena; Iconografía.

\section{Abstract}

The figure of Saint Sebastian is one of the most deeply-rooted in the Christian world since the high middle ages devotions. In this sense, the popularity of this Saint, reached him earned numerous patronage and the affection of the people, so all this was expressed artistically in numerous images. This study aims to analyze the different sizes that arose in the Granada environment, since the end of the 16th century until the middle of the 17 th, the wholesale plastic quality thereof, in addition to being imbued by a certain historical connotations, that extension, influenced by some regions, of devotion to Saint Sebastian.

\section{KEYWORDS}

Sculpture; Granada; $16^{\text {th }}-17^{\text {th }}$ centuries; Alonso de Mena; Iconography. 



\section{INTRODUCCIÓN}

Uno de los santos más populares dentro de la hagiografía cristiana es, sin lugar a dudas, San Sebastián. Quizás lo peculiar del primero de sus martirios, o bien su condición de militar y la posterior utilización ideológica que se hizo de ello, hicieron que este personaje alcanzara altas cotas de fama. En palabras de Emile Mâle, "él fue para los artistas de finales de la Edad Media el mártir por excelencia"1. De hecho, es uno de los santos que más patronazgos ostenta desde antiguo: es patrón de los arqueros, ballesteros (y por extensión estuvo muy vinculado al mundo militar como después veremos), de los tapiceros, de los vendedores de hierro, fue invocado como uno de los grandes protectores contra la peste e incluso es considerado el patrón de los homosexuales, "seducidos por su desnudez de efebo apolíneo"'.

Cuenta la leyenda que este varón, nacido en Narbona (Francia), vivió en el Imperio Romano bajo el mandato de Diocleciano. Habiéndose ganado la amistad tanto de éste como de Maximiano, se convirtió en jefe de la primera cohorte de la guardia pretoriana imperial. Cristiano en la clandestinidad, ayudaba a sus hermanos, encarcelados por la fe, animándolos y visitándolos. Al ser descubierto, el emperador, decepcionado, le obliga a elegir entre ser soldado o seguir a Cristo. Sebastián perseveró en su fe y es condenado a ser asaeteado en el Campo de Marte atado a un árbol. Los soldados se ensañaron con él, dejándole el cuerpo "como un erizo". Mas no muriendo en tan bárbaro suplicio y habiéndose dado por muerto, sería curado por la viuda Irene. El santo, no obstante, volvió en busca del emperador para reprocharle su actitud hacia los cristianos. Nuevamente apresado, esta vez sí sería martirizado apaleándolo y echando sus restos en una cloaca para que los cristianos no recogiesen su cuerpo. No obstante, el santo se apareció a la matrona Lucía (o Lucina) y le indicó el lugar donde estaba su cadáver pidiéndole ser sepultado al lado de los apóstoles ${ }^{3}$.

1 E. Mâle, L'art religieux à la fin du Moyen Âge. Étude sur l'iconographie du Moyen Âge et sur ses sources d'inspiration, París: Armand Colin, 1931, p. 192.

2 L. Réau, Iconografía del arte cristiano. Iconografía de los santos. De la P a la Z (tomo 2, vol. 5), Barcelona: Ediciones del Serbal, 2000, pp. 194-196.

3 S. de la Vorágine, La leyenda dorada (vol. 1), Madrid: Alianza Editorial, 1982, pp. 111-116. Semejante historia relata Pedro de Ribadeneyra en su obra Flos Sanctorum: P. de Ribadeneyra, Flos Sanctorum. Libro de las vidas de los santos. [s. 1.], por Luis Suarez, 1616, pp. 135-141; Réau, Iconografía..., pp. 193-194. 
Por tanto, será la hagiografía cristiana o la proliferación de las diferentes vidas de santos lo que termine determinando la conocida iconografía de San Sebastián, centrándose casi exclusivamente en el momento del martirio del personaje. Especialmente reseñables serán las obras de Santiago de la Voragine, La leyenda dorada, o el Flos Sanctorum de Pedro de Ribadeneyra en este sentido. Si bien, artísticamente, se han representado escenas del santo derribando a los ídolos o exhortando a Marco y a Marcelino, el dramatismo de su martirio, enormemente atractivo para conmover al lector (incidiendo especialmente en la dosis sangrienta y macabra del hecho), y basado en las fuentes históricas, terminó por convertirse en la iconografía más prototípica de San Sebastián ${ }^{4}$.

Las primeras referencias iconográficas del santo datan del siglo $V$ y se hallan en un fresco de la cripta de Santa Cecilia en la catacumba de San Calixto en Roma. San Sebastián aparece acompañado de otros santos togados ${ }^{5}$. Ya en el siglo VII, en un mosaico dedicado al santo en la iglesia romana de San Pedro Advíncula, éste se nos representa como un anciano, con barba, pelo blanco, vestido con túnica y sosteniendo en su mano derecha una coron ${ }^{6}$. Y es que durante muchos siglos, ese prototipo iconográfico se repitió de manera monótona, haciendo hincapié en la figura del hombre ya maduro y venerable que portaba la corona del martirio ${ }^{7}$. El experto estudioso Louis Réau lo argumenta reseñando que "el tipo anciano y barbudo prevaleció hasta el siglo XV, y está justificado por la leyenda que hizo de San Sebastián un capitán de la guardia del emperador"8. Paradójicamente, en Espańa, como también señala este autor, el santo aparece vestido, pero no como militar o centurión como le correspondería. Si bien, a partir del Renacimiento se extiende en Italia el formato de un San Sebastián desnudo al modo de un nuevo Apolo, en tierras españolas, por razones de decencia, el santo se viste, curiosamente, como si de un doncel preparado para la caza se tratase?.

4 H. Delehaye, Les passions des martyrs et les genres littéraires, Bruselas: Société des Bollandistes. Collection Subsidia Hagiographica, 1966, no 13, pp. 205 y 212. Un breve recorrido sobre los datos históricos de la figura de San Sebastián lo encontramos en: M. Castillo Guerrero, "La iconografía de San Sebastián en el arte occidental. Notas para su estudio", en Espacio y Tiempo. Revista de Ciencias Humanas, 16 (2002), pp. 12-16.

5 J. Lanzuela Hernández, "Una aproximación al estudio iconográfico de San Sebastián”, en STUDIUM. Revista de Humanidades, no 12 (2006), p. 232; Castillo Guerrero, "La iconografía de San Sebastián...”, pp. 17-18.

6 Lanzuela Hernández, "Una aproximación...”, pp. 232-233; Réau, Iconografía..., p. 196.

7 J. Darriulat, Sébastien le Renaissant, París: Lagune, 1999, p. 1. Castillo Guerrero denomina coloquialmente a este modelo el tipo "sota de espadas". Castillo Guerrero, "La iconografía de San Sebastián...”, p. 18.

8 Réau, Iconografía..., p. 196.

9 Réau, Iconografía..., pp. 196-197. G. Duchet-Suchaux y M. Pastoureau, Guía iconográfica de la Biblia y los santos. Madrid: Alianza Editorial, 1996, p. 310. 
Será en la Edad Media cuando aparezca un nuevo modelo iconográfico de San Sebastián, rejuvenecido, el tipo del joven acribillado a flechazos. Ambos prototipos convivirán durante un tiempo, triunfando finalmente éste último, debido a la enorme popularidad que alcanzó. Tal es así, que se ha configurado como el icono que el pueblo tiene del santo en mente, una vez superados aquellos reparos que en España se tenían para plasmar su desnudez, imponiéndose los tipos influidos por el renacimiento italiano, generalmente. Para algunos, los comienzos de este modelo habría que datarlos en el siglo XIII ${ }^{10}$, mientras que para otros surgiría en la centuria siguiente ${ }^{11}$. En este sentido, indirectamente se va a ir produciendo un paralelismo entre la figura de San Sebastián y la Pasión de Cristo. Al igual que éste, el santo está atado a un madero y sufre un cruento tormento (no deja de ser una reinterpretación de la imagen de Jesús atado a la columna). Incluso, iconográficamente, esto se plasmará en las flechas que se representen en su cuerpo, que pueden variar entre tres o cinco. Las primeras simbolizarían los clavos de la cruz, mientras que las segundas significarían las llagas del Señor ${ }^{12}$. Y es que, realmente, la contemplación de la imagen de San Sebastián asaeteado, también tenía una función espiritual: suponía para el fiel sufriente que la veneraba una identificación, un estímulo, un alivio o consuelo ante los avatares, dolores, sufrimientos o enfermedades de la vida (v. g. la peste) ${ }^{13}$.

Centrándonos ya en el entorno granadino, la devoción hacia el santo se rastrea como una de las más antiguas de la ciudad. Tras la reconquista del antiguo reino nazarí por parte de los Reyes Católicos, una vez reinstaurado el cristianismo en Granada, la primera referencia documental acerca de San Sebastián se fecha un 20 de mayo de 1531, se trata de la aprobación de estatutos de la cofradía de dicho santo mártir ${ }^{14}$. Poco después, en 1540 , se registra su actividad procesional en las Actas Capitulares de la Catedral. En ella se ratifica la devoción a este santo, previa a esa fecha ${ }^{15}$. Íntimamente ligada a esta cofradía, intitulada de los santos Sebastián y Fabián, se encuentra el que pudo ser el primer espacio de culto dedicado al santo mártir, la ermita de San Sebastián del Violón. Hasta ella realizaron

10 Duchet-Suchaux y Pastoureau, Guía iconográfica..., p. 310; Castillo Guerrero, "La iconografía de San Sebastián...”, p. 20.

11 J. Lanzuela Hernández, "Una aproximación...”, p. 232; M. Castillo Guerrero, "La iconografía de San Sebastián...”, pp. 236-237. Cita a la obra de Jacques Darriulat.

12 Réau, Iconografía..., p. 194; Castillo Guerrero, "La iconografía de San Sebastián...”, pp. 242-243.

13 Castillo Guerrero, "La iconografía de San Sebastián...", pp. 244-245.

14 Archivo Histórico Diocesano de Granada [AHDGr], Legajo 3-F, pieza s/n.

15 Archivo Capitular de la Catedral de Granada [ACCGr], Actas Capitulares, II, fol. 304 ro: "En 16 [de enero de 1540] se trató de petición dada por los Cofrades de San Sebastian, y se acordó iría la procession hasta el humiladero de San Sebastian, y se volvería a decir missa, y predicar en la iglesia mayor; y si no aceptassen esto, se les diesen los ornamentos, que huviessen menester para la fiesta". Hay quien sitúa la fundación en torno a 1531. 
durante varios años su procesión desde la iglesia del Sagrario, como así indica la citada referencia catedralicia. Según la tradición, la dedicación de la ermita pudo realizarse en tiempo de la reconquista, ocupando un antiguo morabito de 1212. Idea para nada descabellada, puesto que junto a su emplazamiento se ubica la histórica entrega de las llaves de la ciudad por parte de Boabdil a los Reyes Católicos. Propio sería que se quisiera dejar constancia de este hecho dedicando un lugar al culto divino. La citada cofradía de los mártires se encargó del culto de la ermita, como así consta de la restauración efectuada en 1615 a sus expensas. Cerca de la confluencia de los ríos Genil y Darro se levantó hacia 1538, por mano de la cofradía, una cruz cobijada por templete, el conocido como humilladero de San Sebastián. En el centro neurálgico de la ciudad, concretamente junto a la plaza Bibrambla, existió desde mediados del XVI una capilla dedicada a San Sebastián. Ésta fue erigida por la citada hermandad, junto con su hospital, para facilitar el culto al santo, ya que la ubicación extramuros de la ermita original imposibilitaba el acceso en tiempo de lluvias. Desde aquí, y desde la iglesia del Sagrario, realizaban sus procesiones hacia la primitiva ermita o sólo hasta el humilladero. Tras la demolición de ambos edificios del centro en 1837, la sede pasó a la parroquial del Sagrario. Curiosamente, en torno a ese foco, se fue manteniendo la cofradía por el gremio de los comerciantes, que históricamente tuvo mucha importancia en la ciudad, y que con el paso del tiempo iría menguando. En los últimos años, se está intentando revitalizar, manteniendo su sede en la iglesia parroquial del Sagrario.

Asimismo, es bastante amplio el culto que recibe San Sebastián en la demarcación de la diócesis granadina. El santo ostenta el patronazgo de numerosas localidades, más de una veintena, como es el caso de Albuñuelas, Alfacar, Arenas del Rey, Bayacas, Benalúa de las Villas, Bubión, Cacín, Dílar, Gabia la Grande, Lanjarón, Laroles, Laujar, Lojilla, Órgiva, Padul...

Especialmente tiene relevancia dicho patronazgo en las comarcas de la Alpujarra y Valle de Lecrín, donde abunda sobremanera. Para explicar este hecho hemos de tener en cuenta un acontecimiento histórico de importancia capital: la Guerra de las Alpujarras acaecida entre 1568 y 1571. En este sentido, la llegada en abril de 1569 de Don Juan de Austria a tierras granadinas influyó enormemente. Parece ser que el hermano natural de Felipe II era bastante devoto de San Sebastián. Tiene sentido que el hábil militar se pusiese bajo la protección de un santo que, como él, compartía el trabajo de las armas. Conforme fue conquistando los distintos municipios sublevados, los fue poniendo bajo el patronazgo del mismo. Esto explicaría la alta concentración de pueblos que tienen como patrón a San Sebastián en la zona ${ }^{16}$. Igualmente, otro factor determinante será consecuencia de lo que acabamos de expresar. Una comarca, La Alpujarra, en la que numerosos

16 M. Barrios Aguilera y V. Sánchez Ramos, Martirios y mentalidad martirial en las Alpujarras. De la rebelión morisca a las Actas de Ugíjar, Granada: Universidad de Granada, 2001, pp. 185-186. 
sacerdotes fueron asesinados por los moriscos levantados, acentuó el concepto de lo martirial. Aquellos sucesos fueron interpretados por la iglesia de la época, en un período donde esta idea era también fomentada y utilizada por la Contrarrefor$\mathrm{ma}^{17}$, para reafirmar la fe de una diócesis que intentaba enraizarse en los orígenes apostólicos. Mártires de La Alpujarra y mártires del Sacro Monte se unían en este envite ideológico. Es lógico, pues, que muchos pueblos viesen el ejemplo de un mártir como San Sebastián un modo de identificación con lo acontecido en la rebelión alpujarreña. De este modo se explicaría la proliferación, en una zona tan acotada, de un mismo patronazgo.

\section{La iconografía escultórica naturalista de San Sebastián en el entorno GRANADINO.}

Antes de abordar las expresiones plásticas que en el panorama escultórico naturalista granadino propició el amplio culto a San Sebastián, hemos de echar la mirada hacia atrás y apreciar otras manifestaciones artísticas previas que sobre el mismo tema podemos encontrar en el entorno.

Desde la reinstauración de la Fe cristiana en la actual provincia granadina, parece que el culto al glorioso mártir miliciano quedó patente y recogido mediante representaciones de su figura. Estas piezas pueden ser consideradas como el prólogo del amplio desarrollo de su iconografía que veremos a continuación. Posiblemente con la llegada de las tropas castellanas de los Reyes Católicos, llegasen también las primeras representaciones de San Sebastián a tierras granadinas. Con total probabilidad respondiesen a obras escultóricas de pequeńo formato, para su fácil traslado, y de carácter gótico tardío. Del mismo estilo serían representaciones pictóricas del santo que pudieran haber venido.

A este primer grupo de piezas puede pertenecer la pequeña talla de San Sebastián, del retablo de San Bartolomé en la iglesia parroquial de San José de Granada. Se trata de una obra de apenas 50 centímetros de altura, de características estilísticas que lo acercan al gótico alemán, como algunas de otras piezas que llegaron con la corte de los Reyes Católicos, caso de la Virgen de la Antigua de la Catedral granadina.

17 Barrios Aguilera y Sánchez Ramos, Martirios y mentalidad martirial..., pp. 97-138; E. Mâle, El arte religioso de la Contrarreforma, Madrid: Ediciones Encuentro, 2001, capítulo 3. En este sentido, cabe recordar que, hasta hace pocos años, el claustro del Seminario Menor de Granada, ubicado en la Plaza de Gracia, en el antiguo convento de Trinitarios Descalzos, se decoraba con numerosos lienzos que representaban a los diferentes sacerdotes martirizados, con sus becas rojas de mártires, y como fondo, se pintaba también su respectivo martirio con una pequeña nota bibliográfica, que sirviese como ejemplo para los jóvenes que en ese lugar se estaban formando. 


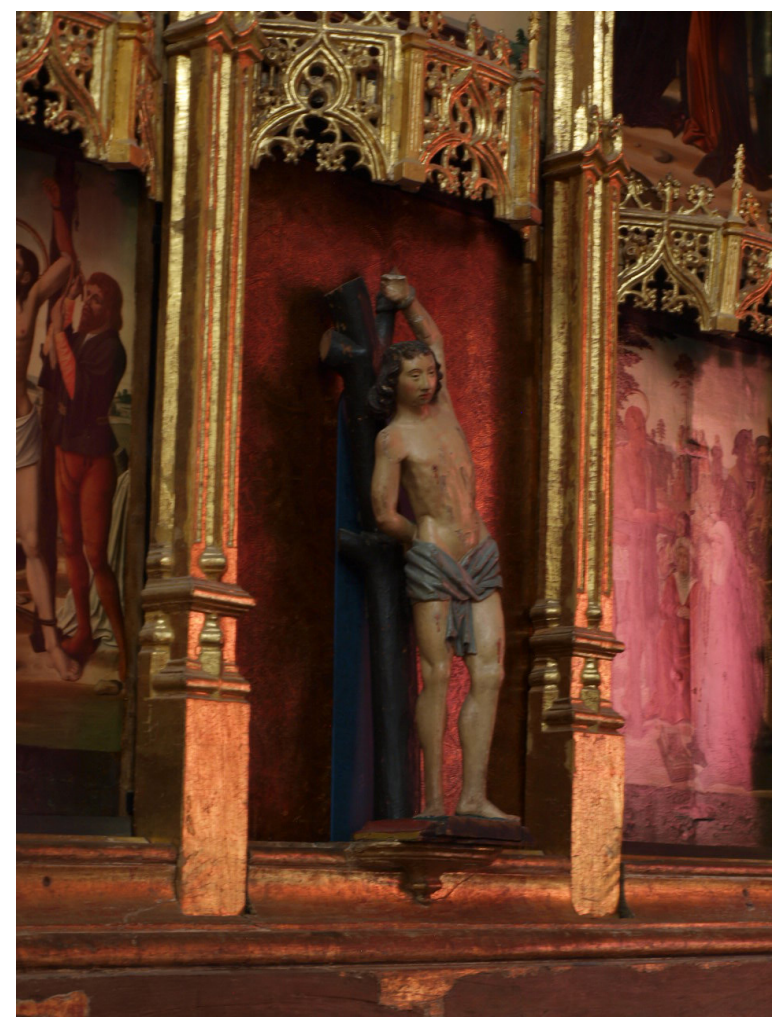

Figura 1. San Sebastián. Iglesia parroquial de San José (Granada). Anónimo, siglo XV. Foto: José A. Peinado Guzmán e Isaac Palomino Ruiz [JAPG/IPR].

Otra pieza que llama poderosamente la atención es la que se venera en la parroquial de Alfornón, en la Haza del Lino alpujarreña. Un San Sebastián de tamaño académico, de estilizada composición y de rasgos algo arcaicos. La figura del santo queda condicionada por la rectitud del tronco, resultando bastante esquemática y de acusada verticalidad. Sucede hasta el punto de que los pies quedan situados sobre el arranque del tronco y no asientan en plano sobre el suelo, dando mayor sensación de ingravidez. Estas características nos llevan a pensar, junto con la sencillez de trabajo en la parte trasera de la imagen, que fuese concebida como talla de altar. Muestra su mirada elevada, gesto serio, los brazos colocados en contraposición uno de otro. Presenta la curiosidad de asir el cuerpo al troco atado por cordeles, a la altura de las muñecas y a la de ambos tobillos. 


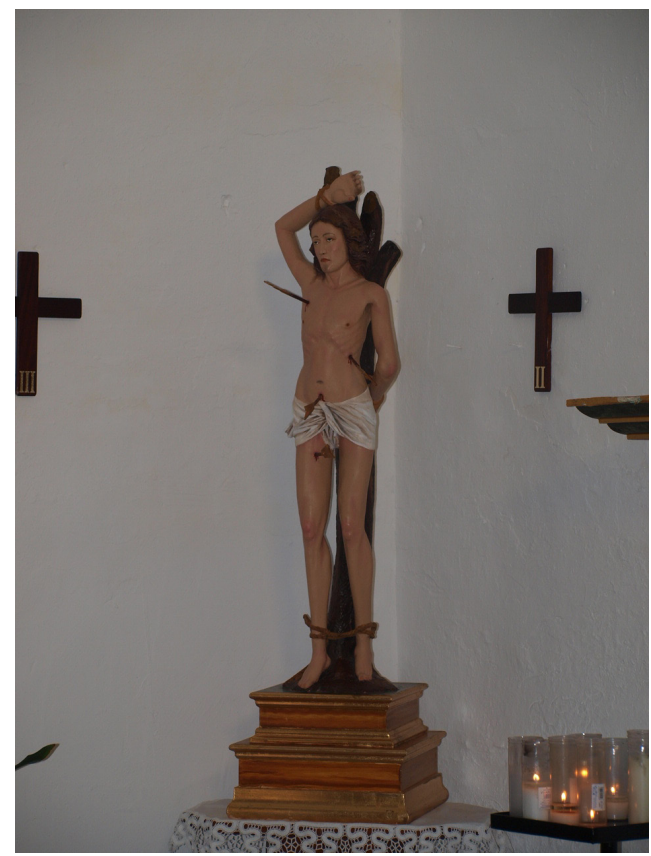

Figura 2. San Sebastián. Iglesia parroquial de San Roque. Alfornón (Granada). Anónimo, siglo XV. Foto: José A. Peinado Guzmán e Isaac Palomino Ruiz [JAPG/IPR].

Estas obras presentadas, u otras similares, debieron ser de las primeras representaciones escultóricas que contemplasen los artistas de los que a continuación vamos a tratar, aún, no siendo referentes plásticos para ellos a la hora de desarrollar su obra, ya que responden a postulados estéticos totalmente diferentes.

En este estudio abordaremos imágenes que creemos salidas de obradores escultóricos netamente granadinos y que se encuadran, como bien indica el título de este artículo, en plena estética naturalista. Hablamos en esencia de tres grandes maestros, Pablo de Rojas, padre del naturalismo escultórico, Bernabé de Gaviria y Alonso de Mena, a quienes atribuimos las piezas que se tratarán a continuación.

Damos inicio a este elenco de piezas "sebastianas" con una talla que ya se muestra naturalista en su resolución. Es la imagen que se venera en la iglesia parroquial de Nuestra Señora de la Paz de Gójar, en plena vega granadina. Se trata de una talla de pequeńo formato que presenta al santo erguido y bien asido al tronco. La disposición del cuerpo en contraposto, dejando marcar una evidente curva praxiteliana, hace de esta obra un claro ejemplo de manierismo escultórico. Los brazos quedan uno elevado sobre la cabeza, con la mano como cubriendo a ésta, y el otro hacia atrás asido al tronco. Esta colocación ya muestra un avance en el proceso conformador de la iconografía de este santo dentro del periodo artístico que nos ocupa, como iremos viendo. 


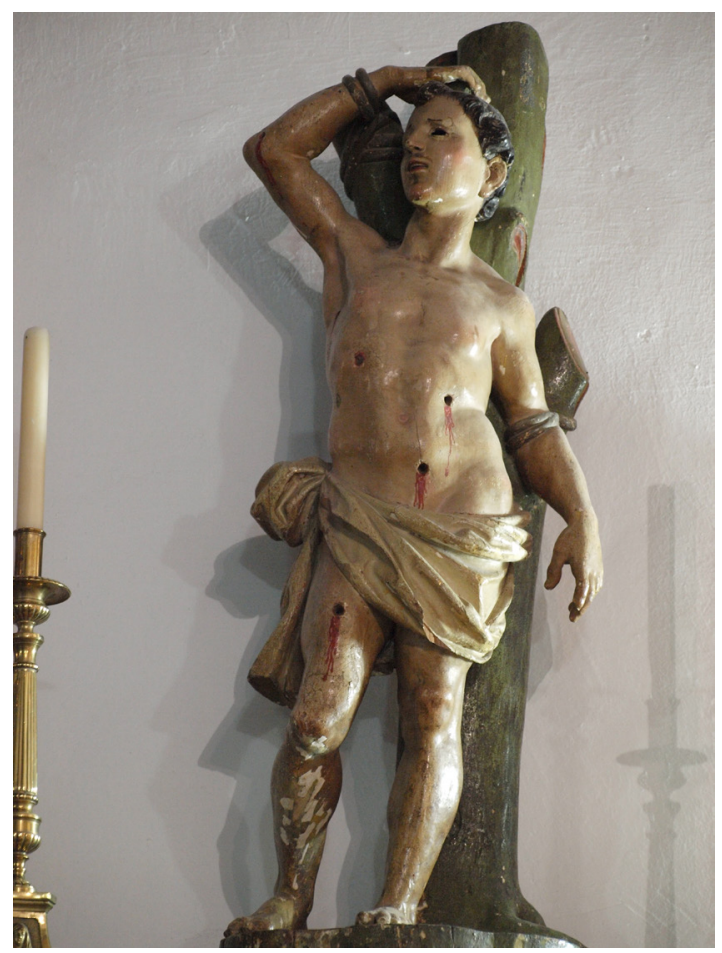

Figura 3. San Sebastián. Iglesia parroquial de Nuestra Señora de la Paz. Gójar (Granada). Anónimo, principios del siglo XVII. Foto: José A. Peinado Guzmán e Isaac Palomino Ruiz [JAPG/IPR].

Una de las imágenes más bellas de San Sebastián que encontramos en el arzobispado granadino se halla en la parroquial de Huétor Santillán, una localidad cercana a la capital. La misma se ubica en el retablo del altar mayor de dicho templo. A primera vista, el primer rasgo que llama la atención es la corporeidad de la talla. Se nos representa la figura de un joven de formas voluminosas, musculadas, al modo de un héroe o dios de la Antigüedad Clásica. No olvidemos que los cánones del naturalismo escultórico, con sus resabios de corte renacentista, exploran en los estilemas greco-romanos.

Dicho esto, contemplamos la imagen de San Sebastián de pie y atado al habitual árbol que compone su iconografía. Pero su semblante no es tan sufriente como triunfante, al modo de un Resucitado, como el que ha vencido al tormento. Es reseńable sobremanera el acusado contraposto que se observa con una marcada línea serpenteante en la pose de la figura. Su cabeza, girada hacia la derecha y mirando hacia el cielo, manifiesta el momento de éxtasis del santo en el trance del martirio. Las facciones del rostro, un tanto desdibujadas por una desafortunada restauración, ofrecen los estilemas propios de la escultura relacionada con Pablo 
de Rojas y su círculo: ojos almendrados sobre los cuales se dibujan cejas inclinadas que acentúan el semblante dramático, nariz recta y boca entreabierta, que deja ver la corona dental superior, y el labio superior suavemente definido, algo muy prototípico de las formas de este período escultórico. Algo similar a lo que sucede con el cabello, ondulado, con rizos marcados, trabajados uno a uno, y con el característico mechón en la frente que seguirán perpetuando escultores posteriores como Martínez Montańés o Alonso de Mena en la primera mitad del siglo XVII. El torso nos muestra un denodado esfuerzo por plasmarnos la belleza ideal del desnudo masculino, algo que los cánones clásicos buscaron claramente en la iconografía de San Sebastián, como nuevo Apolo. Sin llegar a ser notoriamente voluminoso, su definición es clara y rotunda, percibiéndose en los pectorales, abdominales e incluso costillas. Con respecto a las extremidades, el brazo derecho se yergue hacia arriba, como atado, conformando casi un ángulo recto si tomamos como vértice el codo. Su mano diestra, abierta, separa cada uno de sus dedos en gesto dramático. Por el contrario, el brazo izquierdo queda más bajo, también atado y en tensión, mostrándose su mano, en similar dramatismo, a la altura del costado. Las piernas se contemplan fuertes y musculosas, en pose diagonal virando hacia la izquierda, y prácticamente paralelas entre sí, fruto del arranque del contraposto.

La imagen se cubre únicamente con un perizoma que recuerda, de forma mimética, a los que Pablo de Rojas y su círculo elaboran en las iconografías de los crucificados: nudo atado a la altura de la parte derecha cadera, caída en pliegue de

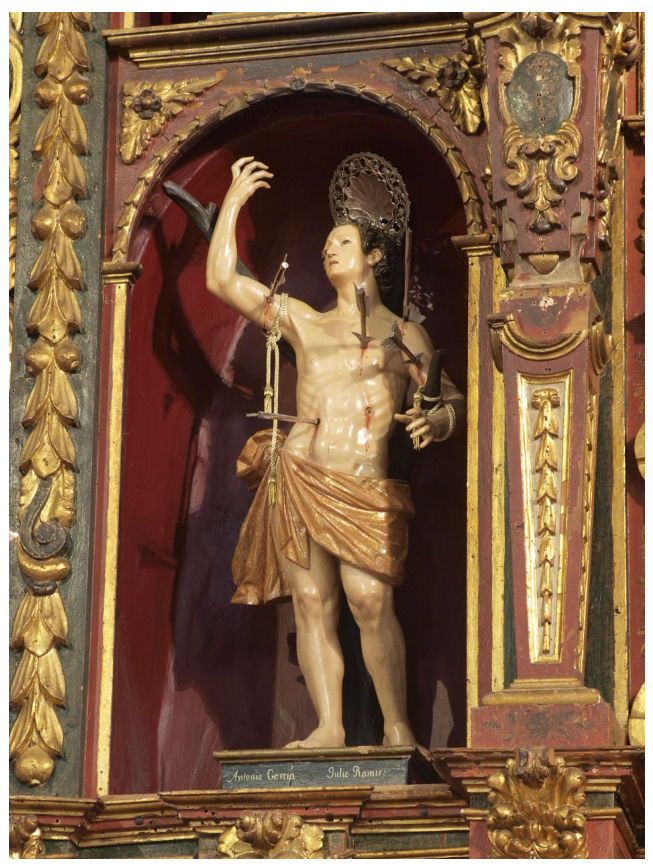

Figura 4. San Sebastián. Iglesia parroquial de La Encarnación. Huétor Santillán (Granada). Atribución a Pablo de Rojas, finales del siglo XVI o principios del siglo XVII. Foto: José A. Peinado Guzmán e Isaac Palomino Ruiz [JAPG/IPR]. 


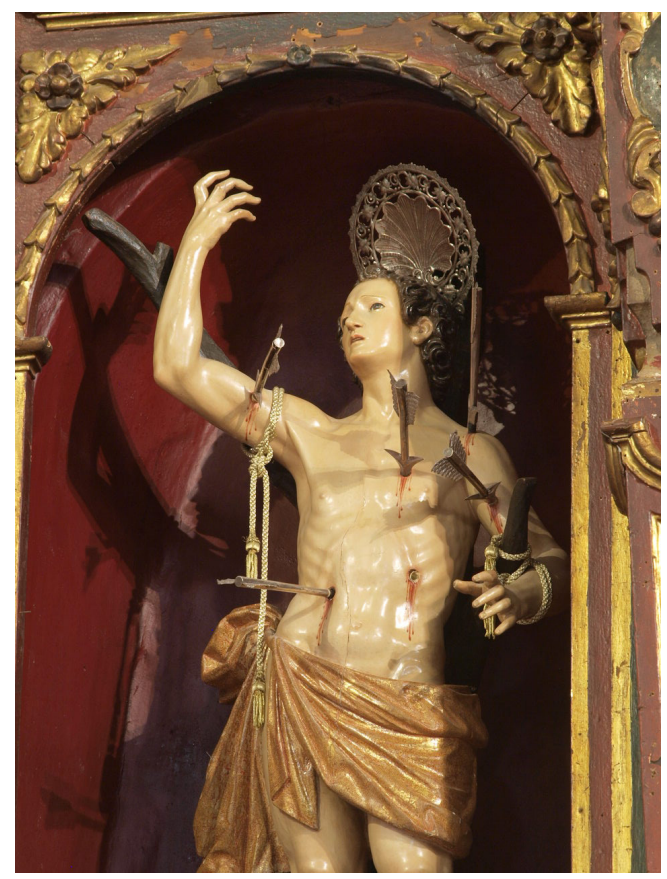

Figura 5. San Sebastián. Iglesia parroquial de La Encarnación. Huétor Santillán (Granada). Atribución a Pablo de Rojas, finales del siglo XVI o principios del siglo XVII. Foto: José A. Peinado Guzmán e Isaac Palomino Ruiz [JAPG/IPR]. Detalle.

corbata y doble plegado en diagonal notoriamente trabajado. La talla se complementa con algún elemento argenteo a modo de exorno. Por un lado, observamos el típico nimbo circular avenerado; por otro lado, vemos también las flechas del martirio, concretamente cuatro. Se aprecia la falta de una, puesto que se contempla el agujero de una de las saetas en la zona costal izquierda. Por tanto, serían cinco las que en su origen tuvo la imagen, símbolo de las llagas de Cristo como ya se dijo. La talla, la encuadramos dentro del círculo de Pablo de Rojas, a principios del siglo XVII, por similitud estilística con otras obras documentadas del padre del naturalismo escultórico en estas tierras.

Con un modelo bastante cercano al de su maestro, pero con un aire manierista en su composición mucho más acentuado, traemos algunas imágenes relacionables con el estilo en que trabajó esta iconografía Bernabé de Gaviria. Conocemos fidedignamente, gracias a la documentación existente, que a su gubia se debe la hechura que se encuentra en la parroquial de Albolote, fechado su encargo en $1603^{18}$. Una talla que, gracias a su estudiada y naturalista anatomía, junto a

18 L. Gila Medina, "Bernabé de Gaviria: continuación y ruptura de los ideales de Pablo de 


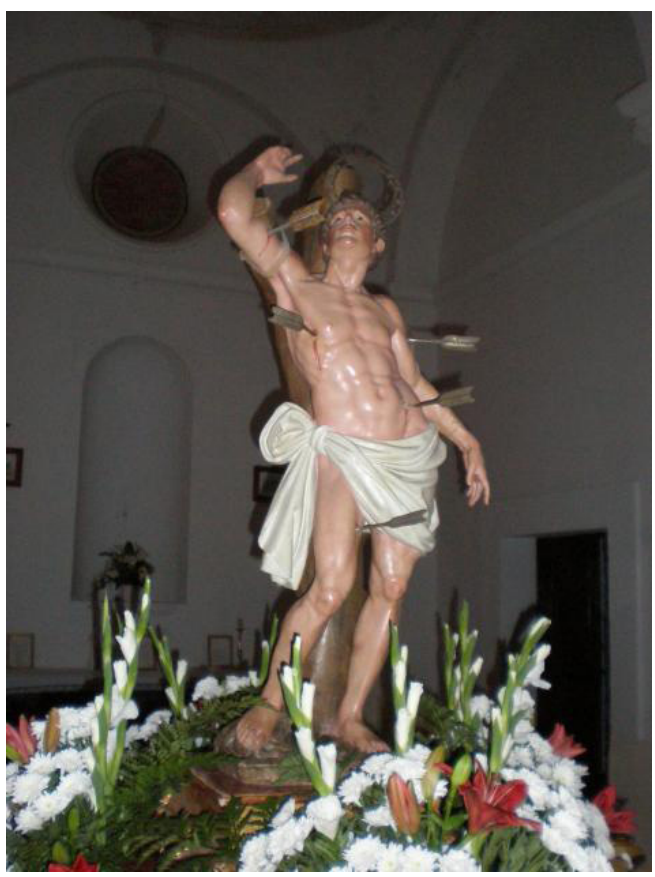

Figura 6. San Sebastián. Ermita de San Sebastián. Pinos del Valle (Granada). Atribución a Bernabé de Gaviria, siglo XVII. Foto: José A. Peinado Guzmán e Isaac Palomino Ruiz [JAPG/IPR].

su conseguida expresión y la elegancia en la composición, supone un hito en las representaciones plásticas de este santo en el entorno granadino.

Similar a éste, nos atrevemos a presentar como obra muy cercana a Bernabé de Gaviria, si no directa de su mano, al San Sebastián de la ermita del mismo nombre en la localidad de Pinos del Valle. Se trata de una talla de tamaño inferior al natural, en la que las formas se presumen notoriamente elegantes y delicadas, a la par que desarrolla una reseńable definición de la musculatura. Especial elegancia se observa en la posición de brazos y manos, así como en la pose del cuello y cabeza. Estos últimos están dispuestos hacia atrás, y levemente girados hacia la izquierda. En ese caso la atención de la mirada queda perdida. Con respecto a las extremidades superiores. A diferencia de la imagen de Albolote, las manos se resuelven de manera algo más naturalista. La derecha y elevada tiende a encoger sus dedos, dejando abiertos al aire el índice y el pulgar. Mientras la izquierda cae de manera sumamente natural. Con ésta culmina el brazo que cae hacia atrás formando una

Rojas", en L. Gila Medina (coord.): La escultura del primer naturalismo en Andalucía e Hispanoamérica (1580-1625). Madrid: Editorial Arco/Libros, 2010, p. 187. 
diagonal compositiva con la extremidad opuesta y el tronco al que éste se anuda. Con estas variaciones podemos decir que Gaviria comienza a innovar sobre el modelo de su maestro Rojas. Muy bien conseguidas resultan las extremidades inferiores, por la movilidad de las mismas mediante el escalonamiento de las rodillas y el juego de líneas, paralelas y oblicuas, que dibujan las piernas. Resaltar también la cabeza menuda, con rasgos pequeños y el característico bigote pictórico con el que Gaviria solía dotar a esta iconografía. Destaca el perizoma de plegado abundante, airosamente anudado sobre la cadera derecha. (ver Fig. 6)

Siguiendo las trazas del modelo previo, mas con una resolución tendente a un mayor hieratismo, se destaca el San Sebastián del Museo de San Juan de Dios Casa de los Pisa (Granada).

Aunque en tamaño inferior a los anteriores, y siguiendo la misma estela compositiva, mostramos la imagen de la parroquial de Picena, en la Alpujarra alta cercana a la frontera almeriense. En el caso de Picena, si bien, en cuanto a las formas nos encontramos con dos imágenes muy parecidas, la consecución de esta última resulta notoriamente de inferior calidad técnica tanto en el rostro, como en la resolución de las extremidades superiores e inferiores. Desafortunadas intervenciones posteriores entorpecen la contemplación conjunta y auténtica de la imagen, caso de la mano izquierda recompuesta y el opaco repolicromado. A pesar de ello el grácil contraposto permite apreciar una dinámica y conseguida anatomía. La cara, totalmente girada en actitud implorante, un peinado menudo que deja claramente a la vista la estructura craneal y remarcado en copete o la disposición del perizoma son estilemas propios que nos permiten acercar esta obra al quehacer de Bernabé de Gaviria. Asimismo, se puede referenciar también la talla de la localidad granadina de La Zubia. (Ver Fig. 7 y Fig. 8).

En la misma línea se puede ubicar la imagen que se venera en el pueblo de Quéntar. Presenta una disposición más relajada en cuanto al contraposto, siendo de bastante similitud a las anteriores en el conjunto de los rasgos: cabeza menuda y girada, facciones pequeñas del rostro, disposición de las extremidades. Destacar que en la colocación del brazo y mano derechos sigue más de cerca la talla de Albolote. Por las características expuestas que presentan estas tres últimas obras analizadas, podríamos encuadrarlas cronológicamente en la primera década del siglo XVII, periodo donde Gaviria desarrolla este tipo de modelo, aún con puntuales pervivencias de la herencia de Pablo de Rojas.

Marcando una posible línea evolutiva en la representación iconográfica de San Sebastián, ésta ha de ir íntimamente ligada al estilo o modo representativo propio de cada escultor. Una variante mínima de los modelos manieristas de Pinos del Valle y Picena es el de Ogíjares, imagen patronal que se encuentra en la iglesia de Santa Ana. Se trata de una talla de tamaño académico. Mantiene un 


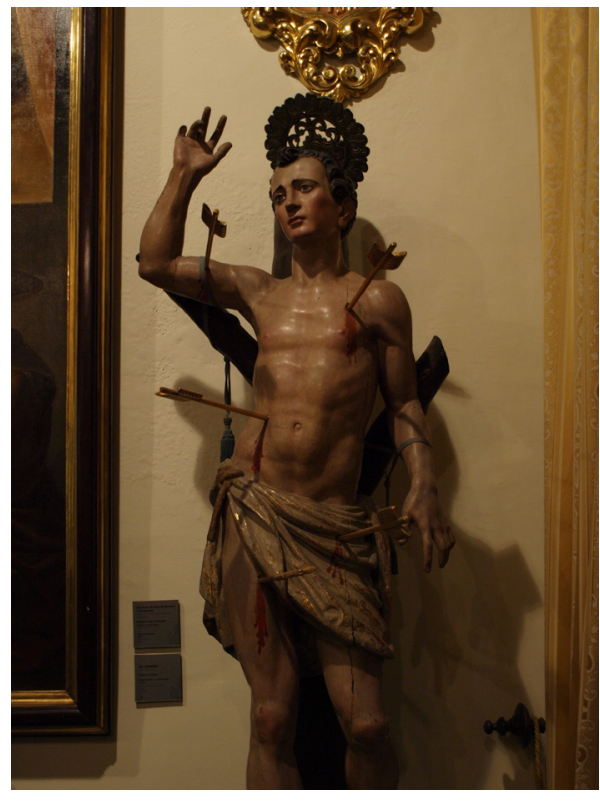

Figura 7. San Sebastián. Museo de San Juan de Dios- Casa de los Pisa (Granada). Atribución al taller de Bernabé de Gaviria, siglo XVII. Foto: José A. Peinado Guzmán e Isaac Palomino Ruiz [JAPG/IPR].

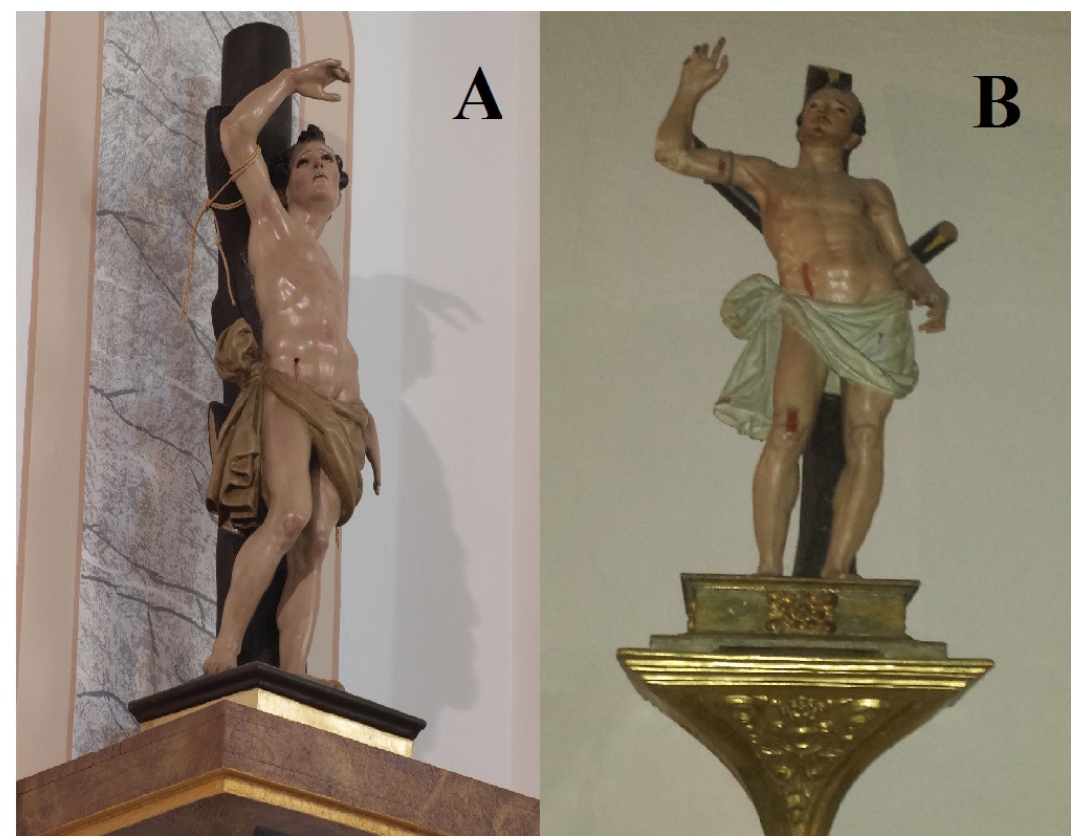

Figura 8. A San Sebastián. Iglesia parroquial de San Cecilio. Picena (Granada). Atribución al taller de Bernabé de Gaviria, siglo XVII. B San Sebastián. Iglesia parroquial de La Asunción. La Zubia (Granada). Atribución al taller de Bernabé de Gaviria, siglo XVII. Foto: José A. Peinado Guzmán e Isaac Palomino Ruiz [JAPG/IPR]. 
ritmo compositivo cercano a los que hemos relacionado con Gaviria, siendo este un contraposto más suave. Si bien, varía a la hora de disponer las extremidades superiores. El derecho bajo y extendido con la mano abierta, el izquierdo elevado y su mano igualmente abierta con los dedos en graduación, hacia donde parece dirigirse la mirada del santo. Una disposición parecida ya presentó Pablo de Rojas en sus "san sebastianes", y veremos que se mantiene en algunas de las tallas que aquí presentamos relacionables con Alonso de Mena. Presenta una anatomía de musculatura desarrollada y bien conseguida en el trabajo de talla. La cabeza es menuda, de marcada estructura ósea, especialmente en la mandíbula. El rostro es de facciones reducidas: cejas angulosas y marcadas, orejas y nariz pequeñas. La expresión del santo es de acusado dramatismo, acentuada por unos ojos pequeños y clamorosos, así como una boca abierta, de labios finos, y perfiles muy definidos, y tren dentario superior visible. Estos rasgos faciales se aprecian de igual manera en el San Juan Bautista de Cozvíjar, de $1622^{19}$ o en el Crucificado de Mecina Fondales $^{20}$. Se atisba la sombra de la barba y un incipiente bigote. El cabello se dispone peinado en dos mechones sobre una amplia frente. En su caída, evoluciona el cabello desde el liso para terminar en mechones rizados y menudos. Esta manera de disponer el cabello lo encontramos en piezas documentadas de Alonso de Mena y Escalante, caso del San José que preside la portada del Monasterio de Carmelitas Descalzas de Granada, contratado en $1624^{21}$, o un busto relicario de la Capilla Real. (ver Fig. 9).

Destaca el perizoma, anudado con cordel sobre la zona baja de la cadera, dejando al descubierto la zona del nudo. Un paño de abundante plegado y gran movimiento, especialmente en la caída del nudo con terminación quebrada. Todas las características expuestas enlazan de nuevo con los estilemas acuñados en la obra de Alonso de Mena, en un periodo inicial aún dependiente de los modelos de Pablo de Rojas. Por tanto, se puede encuadrar esta imagen cercana a la década entre 1620 y 1630. Se presenta asaeteado por cuatro flechas argénteas, así como el gran nimbo avenerado que lo corona. Debió quedar asido al tronco mediante cordeles, hoy desaparecidos.

No se puede obviar otra representación del santo mártir, localizada en la misma población, en esta ocasión en la iglesia de Santa María de la Cabeza. Se trata de una pequeña obra en terracota, de composición mucho más dinámica, que-

19 L. Gila Medina, "Alonso de Mena y Escalante, escultor, ensamblador y arquitecto”, en L. Gila Medina (coord.): La consolidación del Barroco en la escultura andaluza e hispanoamericana. Granada: Universidad de Granada, 2013, p. 52.

20 J. A. Peinado Guzmán, "El Crucificado en La Alpujarra granadina. Nuevas piezas relacionadas con la obra de Pablo de Rojas y Alonso de Mena", en De Arte. Revista de Historia del Arte, no 14 (2015), pp. 73-74.

21 Gila Medina “Alonso de Mena y Escalante...”, p. 54. 


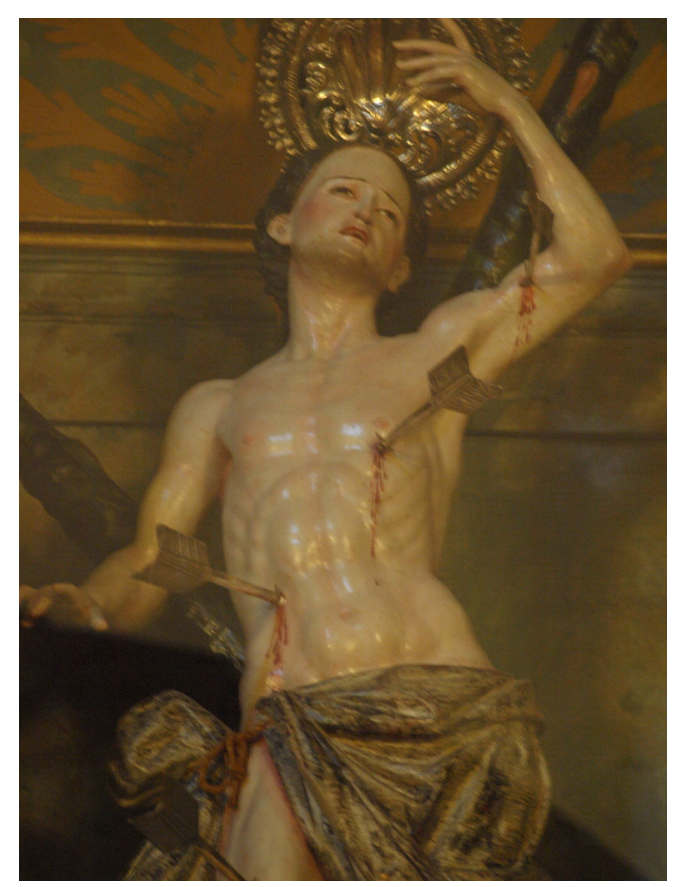

Figura 9. San Sebastián. Iglesia de Santa Ana. Ogíjares (Granada). Atribución a Alonso de Mena, siglo XVII. Foto: José A. Peinado Guzmán e Isaac Palomino Ruiz [JAPG/IPR].

brada y de gran detallismo. Su estilo ha sido relacionado con el propio de los hermanos García ${ }^{22}$, exponentes del naturalismo escultórico granadino del primer tercio del siglo XVII.

Como un paso más en el proceso de conformación de una estética propia, hacia un modelo más estático y sobrio en su expresión, se manifiesta el San Sebastián de Órgiva. Una talla de tamaño inferior al natural que preside su propia ermita. Aunque presenta en su línea compositiva similitud con el modelo de Gaviria ya analizado, el brazo izquierdo unido al torso y un ligero contraposto, el conjunto de la obra delata ya otra mano y otra idea del primer cuarto del siglo XVII. A ello nos llevan la menor definición de las extremidades inferiores, siendo extensible este detalle en las manos y una belleza que deja de ser idealizada, con rasgos más duros. Una cabeza más erguida, rotunda y amplia en su volumen; el tratamiento del cabello en mechones más pequeños y trabajados; la posición del brazo elevado un tanto forzada y, sobre todo, la forma de trabajar el perizoma con un plegado

22 J.J. López-Guadalupe Muñoz, "Forma y expresión en los inicios del naturalismo en la Escultura Granadina. Lectura y relecturas sobre los Hermanos García", en L. Gila Medina (coord.): La consolidación del Barroco en la escultura andaluza e hispanoamericana. Granada: Universidad de Granada, 2013, p. 237. 
más abundante y quebrado, son características que permiten vincular esta pieza con el círculo de Alonso de Mena. Siempre en una posible transición desde el estilo aprendido de su maestro Rojas, como veíamos en la atribución de Huétor Santillán, a la definición del suyo propio.

De semejantes trazas al mencionado de Huétor Santillán, incluso podríamos decir que una imagen hermana de ésta es la del San Sebastián de la localidad alpujarreña de Bayacas (Granada). Ambas comparten un esquema compositivo idéntico: de su pierna derecha se establece un segmento con la parte izquierda de la cadera; desde ahí otro con el brazo izquierdo, para finalmente dibujar el último con la cabeza virada a la siniestra. Ahora bien, nos encontramos ante una versión mejorada y enriquecida, no sólo en la belleza, sino también en el dramatismo de la misma. Esta obra es atribuible a Alonso de Mena, fechándose la misma en el primer cuarto del siglo XVII. Toda vez que la similitud de formas es palmaria, nos centraremos únicamente en lo reseñable, como por ejemplo la cabeza, rotunda y de una emotividad sublime, con rasgos más duros que la atribuida a Rojas. El cabello, con rizos modelados uno a uno, gruesos y bien definidos, sigue los modelos citados de principios del XVII. Se denotan, asimismo, unas cejas más marcadas a la par que una boca visiblemente más conseguida. De igual modo, el perizoma, nuevamente recordando los realizados para los crucificados, sigue el tipo que Alonso de Mena ejecuta a tal efecto en numerosos de sus cristos. La disposición del paño, en este caso, es opuesta al del ejemplo previamente descrito. Complementan el adorno el habitual nimbo circular y las clásicas flechas, siendo sendos elementos metálicos. Con respecto al número de flechas, también en esta muestra se contabilizan cuatro. En este ejemplo no se aprecia la quinta herida, que pudo ser ocultada en la reciente restauración que se aprecia se le ha aplicado. (Ver Fig.10 y Fig. 11).

De gran similitud a la talla de Bayacas, con la salvedad del deterioro en su estado de conservación, se muestra la imagen de la Parroquia de La Malahá.

Siguiendo con la estela del trabajo de Alonso de Mena, nos atrevemos a presentar como imagen relacionada con su estética la del patrón de la localidad de Albuñuelas. Hablamos de una imagen de tamaño cercano al natural, algo que la hace desmarcarse de lo habitual como hemos podido ver. En ella la elegancia de la curva praxiteliana se diluye para dar paso un aparente hieratismo. El dinamismo de la figura radica principalmente en un leve movimiento de cadera hacia la izquierda, debido a la flexión de su pierna derecha que deja más atrás. Ello obliga a girar el torso y la cabeza, que deja caer también hacia atrás, todo muy sutilmente. Destacable de esta imagen es, sin duda, la consecución de su anatomía fuerte y vigorosa. Se denota bien estudiada y trabajada como refleja la tensión del cuello en su músculo esternocleidomastoideo. Llama la atención, posiblemente por curiosa, la posición del brazo y mano derechos más asidos al cuerpo que lo habitual 

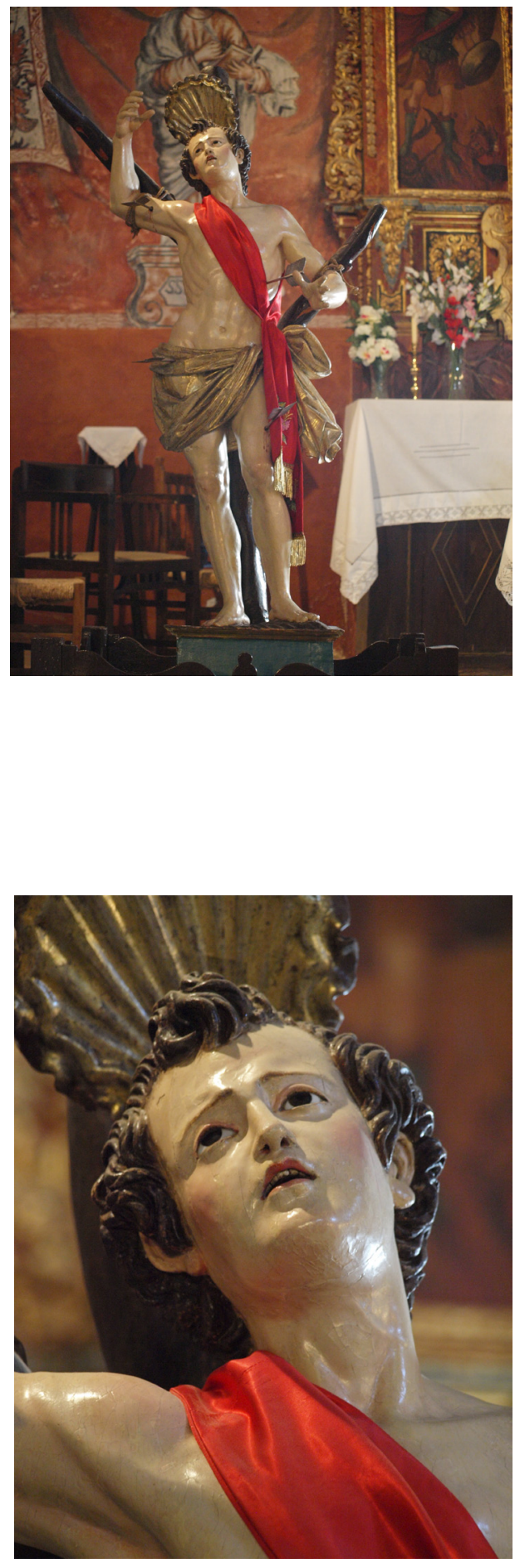

Figura 10. San Sebastián. Iglesia parroquial de San Sebastián. Bayacas (Granada). Atribución a Alonso de Mena, siglo XVII. Foto: José A. Peinado Guzmán e Isaac Palomino Ruiz [JAPG/IPR].

Figura 11. San Sebastián. Iglesia parroquial de San Sebastián. Bayacas (Granada). Atribución a Alonso de Mena, siglo XVII. Foto: José A. Peinado Guzmán e Isaac Palomino Ruiz [JAPG/IPR]. Detalle. 
en este tipo de representaciones. Viste la imagen faldellín de tela sobrepuesto, que impide analizar la mano en sí y el perizoma tallado. Manifiesta un rostro de rasgos algo duros, de expresión sufriente: boca abierta y ojos clamorosos. El tratamiento del cabello es menudo y trabajado en definidos mechones cortos. El volumen del casco de la cabeza, bien redondeado y orlado por los mechones desarrollados, coincide casi miméticamente con la pieza homónima de Bayacas. Muestra el característico copete de las obras vinculadas a la estética a Alonso de Mena, así como los mechones sobre sendas orejas. No queda descabellada la filiación de esta obra con el patriarca Mena, dadas las características estilísticas que presenta la imagen, y más si tenemos en cuenta que para esta localidad talló un Crucifijo en $1620^{23}$, amén de otras tallas para localidades cercanas ${ }^{24}$.

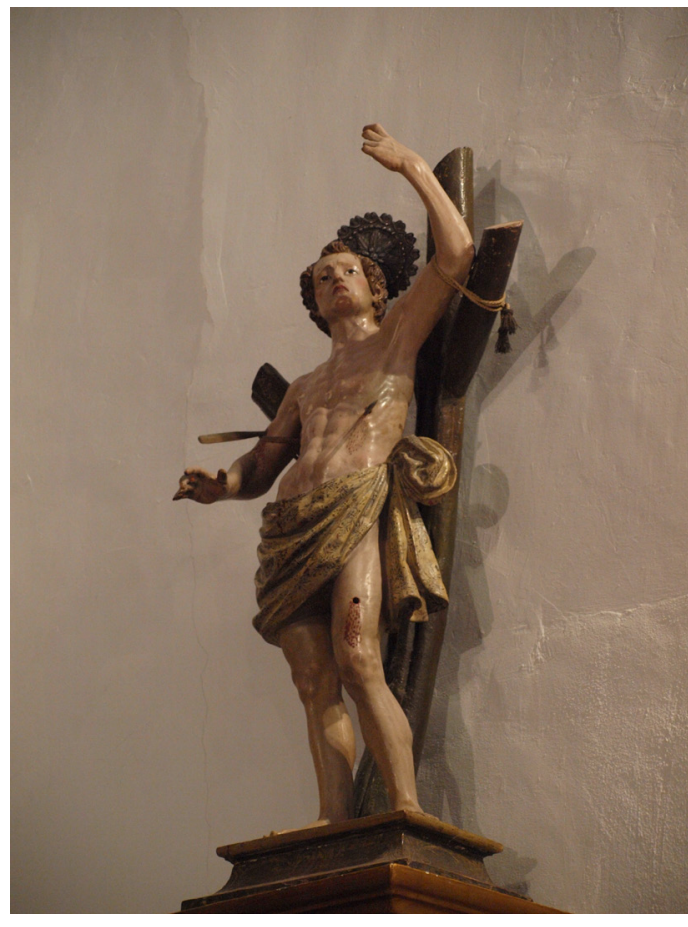

Figura 12. San Sebastián. Iglesia parroquial de la Inmaculada. La Malahá (Granada). Atribución a Alonso de Mena, siglo XVII. Foto: José A. Peinado Guzmán e Isaac Palomino Ruiz [JAPG/IPR].

23 L. Gila Medina, "Un Crucificado temprano de Alonso de Mena: el de la iglesia parroquial de Albuñuelas (Granada)", en Cuadernos de Arte de la Universidad de Granada, no 40 (2009), pp. 99-105.

24 Como se menciona anteriormente, Alonso de Mena talla para Cozvíjar un San Juan Bautista, en 1622. Aún más cercano geográficamente resulta el San Cristóbal que en 1631 realizara para Restábal. Por extenso en I. Palomino Ruiz, "La ermita de San Cristóbal de Restábal (Granada). Historia y arte de un espacio secularizado", en J. A. Peinado Guzmán y M. A. Rodríguez Miranda (coords.): Lecciones barrocas: aunando miradas. Córdoba: Asociación "Hurtado Izquierdo", 2015, pp. 126-154. 


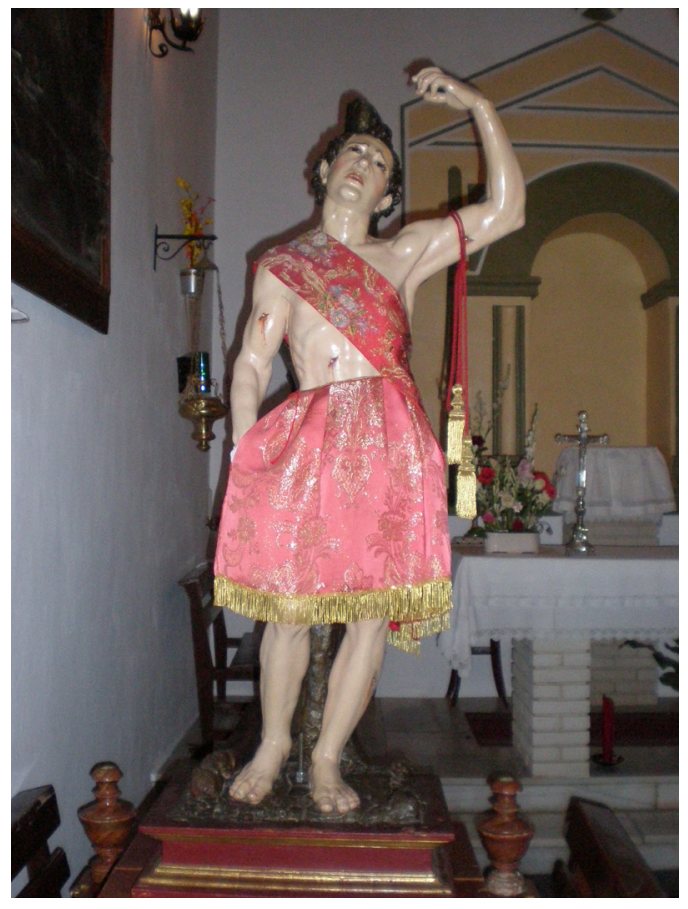

Figura 13. San Sebastián. Iglesia parroquial de Nuestro Salvador. Albunuelas (Granada). Atribución al taller de Alonso de Mena, siglo XVII. Foto: José A. Peinado Guzmán e Isaac Palomino Ruiz [JAPG/IPR].

\section{Conclusiones}

Por lo general presentan un tamańo inferior al natural, y en gran porcentaje inferior incluso al que consideramos académico. Se trata de un factor común, no sólo en las imágenes aquí estudiadas, sino en gran porcentaje de tallas de esta iconografía extendidas a lo largo de una amplia geografía. En el plano artístico, muestran siempre una anatomía desarrollada y bien conseguida, fruto de un exhaustivo estudio del natural y de las estampas tenidas por referentes para la propagación del modelo inspirado directamente en la Antigüedad clásica.

Aún, con leves variaciones, el modelo se mantiene continuamente en las representaciones que podemos analizar en el periodo del naturalismo escultórico granadino. Un periodo de tiempo en que se registran la mayoría de obras escultóricas de esta iconografía martirial. Una representación que apenas tiene repercusión superada la primera mitad del siglo XVII, salvo en contadas ocasiones. Ello puede responder al vínculo con los sucesos martiriales en el territorio estudiado, como ya se indicó al inicio.

Suelen venerarse en ermitas que quedan dentro del entramado urbano: Albuñuelas, Órgiva o Quéntar. Si bien algunos casos quedan fuera del mismo como ocurre en Alfacar, situada en el cementerio de la localidad. Algunas de estas imágenes que hoy se ubican en los templos parroquiales proceden de ermitas propias, caso de Albolote. 
Se les suele ataviar con una banda de gala, generalmente bordada en oro sobre tela roja, por el sentido martirial de la representación. También lucen banderas o estandartes, sujetos a la mano que extiende hacia abajo, posible alusión al carácter militar del santo. En algunos casos aún mantienen el faldellín o faldilla, prenda que al parecer fue muy habitual en el ajuar de este santo, y que ha ido desapareciendo con el paso del tiempo.

Para terminar se citan una serie de imágenes, de tamaño inferior al académico y mediana calidad, que completarían el elenco de la difusión de este modelo iconográfico en el denominado naturalismo escultórico granadino. Dichas tallas se localizarían en las poblaciones de Pórtugos, Gójar, Otura, Dílar, Las Gabias y Lanjarón. 